\title{
Clinical Utility of Viscoelastic Tests of Coagulation (TEG/ROTEM) in Patients with Liver Disease and during Liver Transplantation
}

\author{
Susan V. Mallett, FRCA ${ }^{1}$ \\ ${ }^{1}$ Department of Anaesthesia, Royal Free London NHS Trust, London, \\ United Kingdom \\ Address for correspondence Susan V. Mallett, FRCA, Royal Free Hospital, \\ Pond Street, London NW3 2QG, United Kingdom \\ (e-mail: Susan.mallett@nhs.net). \\ Semin Thromb Hemost 2015;41:527-537.
}

\begin{abstract}
Keywords

- coagulation

- liver disease

- viscoelastic tests

The concept that patients with stable liver disease are at an increased risk of bleeding, based solely on abnormalities of conventional coagulation tests such as prothrombin time (PT) and international normalized ratio (INR), is now recognized to be an overly simplistic interpretation of an extremely complex situation. These tests are in fact very poor predictors of bleeding in patients with liver disease who undergo invasive or surgical procedures. Commercially available whole blood viscoelastic tests (thromboelastography [TEG] and thromboelastometry [ROTEM]) evaluate the kinetics of coagulation from initial clot formation to final clot strength. These dynamic tests provide a composite picture reflecting the interaction of plasma, blood cells, and platelets, and more closely reflect the situation in vivo than do PT/INR, which are performed on plasma samples and measure isolated end points. Despite prolonged PT/INR and low platelet counts, viscoelastic tests are within normal range in many patients with both acute and chronic liver disease, commensurate with the concept of rebalanced hemostasis, and in keeping with the fact that an increasing number of these patients undergo liver transplantation without the need for blood or blood products. In addition, these tests reveal important additional information, such as the presence of hypercoagulability and a prothrombotic state, and also information about the presence of endogenous heparinoids associated with vascular endothelial damage, due to sepsis or acute inflammation. This review provides an overview of the current literature on the potential clinical utility of viscoelastic tests of coagulation in patients with liver disease.
\end{abstract}

The prothrombin time (PT) and international normalized ratio (INR) are used in scoring systems (Child-Pugh, MELD, UKELD) in chronic liver disease (CLD), and as a prognostic tool for dynamic monitoring of hepatic function in acute liver disease. Abnormalities of these tests are also widely interpreted as demonstrating an underlying bleeding diathesis and coagulopathy in patients with liver disease, and continue to influence clinical management decisions. However, these tests are neither good predictors of bleeding risk in liver disease, nor do they provide sufficient information to optimize the management of bleeding events. ${ }^{1,2}$ The shortcomings of the classic interpretation of the coagulopathy of liver disease have been increasingly recognized in recent years. ${ }^{3}$ There has been a paradigm shift in the understanding of hemostasis in these patients, which is now described as being "rebalanced," albeit with a much reduced functional reserve. ${ }^{4}$ Thrombin generation (TG) in patients with liver disease is much better conserved than previously thought when the test conditions are adapted to reflect the contribution of the anticoagulant pathways, ${ }^{5}$ and it is also recognized that there is an increased risk of thromboembolism in patients with CLD, who should not be considered to be "autoanticoagulated." 6 Clinically, this "rebalanced" hemostasis is reflected in the fact that an increasing number of patients with CLD can undergo published online June 6, 2015
Issue Theme Hemostatic Dysfunction in Liver Diseases; Guest Editors: Ton Lisman, PhD, and Hau C. Kwaan, MD, FRCP.
Copyright $\odot 2015$ by Thieme Medical Publishers, Inc., 333 Seventh Avenue, New York, NY 10001, USA. Tel: +1(212) 584-4662.
DOI http://dx.doi.org/ 10.1055/s-0035-1550434. ISSN 0094-6176. 
major abdominal surgery, such as liver transplantation (LT), without the need for blood or blood products. ${ }^{7}$ In addition, although patients with liver disease broadly share the same pattern of coagulopathy as defined by conventional coagulation tests (CCTs) (raised PT/INR and low platelet count), there are notable differences between different types of liver disease. For example, cholestatic disorders such as sclerosing cholangitis and primary biliary cirrhosis are associated with hypercoagulability and platelet hyperreactivity, ${ }^{8}$ and patients with nonalcoholic steatohepatitis (NASH) are relatively prothrombotic, with high levels of plasminogen activator inhibitor type 1 , and a higher incidence of thrombosis. ${ }^{9}$

TG assays have revealed important new information on hemostasis in liver disease, but these tests are not readily available. In addition, TG assays are generally performed in platelet poor plasma and therefore lack information on protein-cell interactions. Whole blood global viscoelastic tests (VETs) of coagulation are increasingly used for pointof-care (POC) analysis of the complex coagulopathies that can occur during cardiac surgery and following major trauma. $^{10,11}$ They differ from CCTs as they evaluate the kinetics of coagulation from initial clot formation to final clot strength. These dynamic tests provide a composite picture reflecting the interaction of plasma, blood cells, and platelets, and more closely reflect the situation in vivo than do CCT, as these are performed solely in plasma and measure only isolated end points. In addition, VET provide valuable information on the presence and severity of fibrinolysis and also hypercoagulability. ${ }^{12}$ Since the early 1980 s, VET have been used for POC coagulation monitoring during LT. ${ }^{13}$ The possibility that there may be more clinical benefit in using VET rather than CCT to assess and stratify bleeding or thrombotic risk in patients with liver disease is an idea that is gaining increasing traction, but this will require prospective clinical outcome studies. ${ }^{14}$ To date, no studies have directly tested whether global tests (TG and VET) are able to usefully predict procedural bleeding risk in patients with liver disease, but given that the many inadequacies of conventional tests are now widely appreciated, this is an area that requires urgent research. ${ }^{15}$

\section{Viscoelastic Tests of Coagulation (TEG/ROTEM)}

Although routine coagulation tests (PT; activated partial thromboplastin time [aPTT]) provide valuable information regarding the quantitative status of procoagulant proteins, they ignore the contribution of cellular elements and endogenous anticoagulant factors. ${ }^{16}$ At the time these tests are concluded, only a fraction $(<5 \%)$ of the total thrombin that will be generated during the process of coagulation has formed; thus they can give only limited information about the overall hemostatic status. ${ }^{17}$ In addition, they are relatively insensitive to some thrombin-dependent reactions associated with normal hemostasis, for example, activation of platelets and the anticoagulant protein $C .{ }^{18}$ Hemostatic assays that demonstrate the interactivity of the major phases and components of the hemostatic process better represent hemo- static capacity, and differentiate the mechanisms related to clotting abnormalities. ${ }^{19}$

Clot formation involves the dynamic interaction between the vascular endothelial wall, platelets, von Willebrand factor (VWF), pro- and anticoagulant factors, and blood flow. The cell-based model of coagulation, ${ }^{20}$ as opposed to the traditional description of intrinsic and extrinsic pathways, emphasizes the role of platelets in intact TG and highlights the importance of the dynamics of TG. ${ }^{21}$ For hemostasis to occur effectively, there must be sufficient TG (coagulation factors and platelets), adequate substrate (fibrinogen), and clot stability. VET measure changes in clot tensile strength over time and give information on the dynamics of clot formation (coagulation factor and anticoagulant activity), clot strength (platelets and fibrinogen), and clot stability (fibrinolysis and factor XIII).

\section{Principles of Thromboelastography}

There are two commercially available devices, both based on Hartert's original invention in 1948,22 the TEG (Haemonetics Corporation, Braintree, MA) and the ROTEM (TEM International GmbH, Munich, Germany). Thromboelastography (TEG) and thromboelastometry (ROTEM) measure the viscoelastic properties of a developing clot in a sample of whole blood, under low shear conditions. They provide real-time information about the quality of the clot and the kinetics of its formation (-Fig. 1). Detailed descriptions of the principles of these machines and their derived parameters can be found in several excellent reviews. ${ }^{23,24}$ Different activators and reagents can be used to increase diagnostic capabilities, for example, heparinase to reverse heparin, tissue factor (TF) and kaolin in the "rapid TEG" to gain accelerated information on clot strength and stability, and FIBTEM (ROTEM) or functional fibrinogen (TEG) for information on fibrinogen levels and to guide fibrinogen therapy.

Although these machines provide very similar information, algorithms for hemostatic interventions based on one technology are not directly transferable to the other. ${ }^{25}$ Currently, VET are classified as POC tests of moderate complexity, and it is essential that personnel running the tests are adequately trained and that the equipment is subject to standard quality management procedures. ${ }^{26}$ Nevertheless, VETs suffer from a unique set of preanalytic and analytic variables that impact test reliability and reproducibility. ${ }^{27}$ The next generation of these machines, such as the TEG $6 \mathrm{~s}$, will be truly POC tests, with ease of use provided by cartridge technology and machine portability (www.Haemonetics $\left.{ }^{\circledR} . c o m\right)$.

\section{Correlation of Standard Coagulation Tests and Viscoelastic Tests}

PT/INR: Correlation between PT/INR and reaction/clotting time $(\mathrm{R} / \mathrm{CT})$ is poor $(r=0.24-0.37) .{ }^{25,28}$ The lack of correlation between PT/INR and R/CT may be explained by several factors, such as different activators, specimens (whole blood vs. plasma), and the fact that $\mathrm{R} / \mathrm{CT}$, unlike INR, reflects the balance of both pro- and anticoagulants. This may be an 


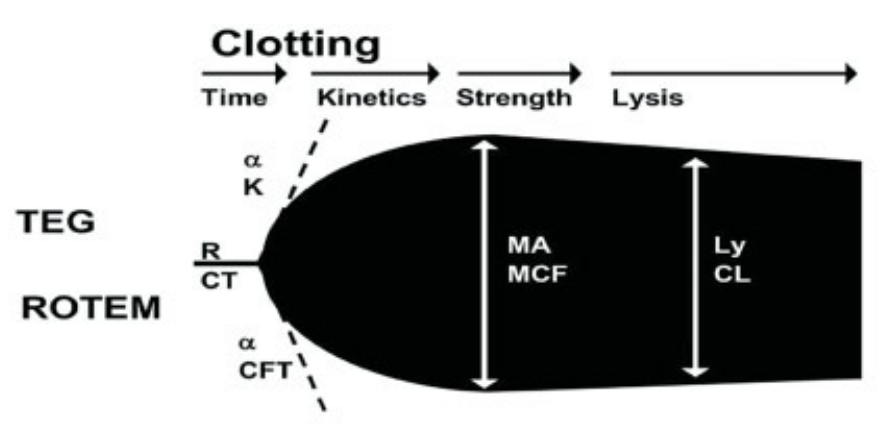

\begin{tabular}{|c|c|c|c|}
\hline & TEG & ROTEM & \\
\hline $\begin{array}{l}\text { Clot initiation or } \\
\text { Clotting time }\end{array}$ & $\mathrm{R}$ (reaction time) & CT (clotting time) & $\begin{array}{l}\text { Period of initial fibrin } \\
\text { formation }\end{array}$ \\
\hline \multirow[t]{2}{*}{ Clot Kinetics } & $\mathrm{K}$ ( $\mathrm{K}$ value) & $\begin{array}{l}\text { CFT (clot formation } \\
\text { time) }\end{array}$ & $\begin{array}{l}\text { A measure of the } \\
\text { speed to reach a } \\
\text { specific level of clot } \\
\text { strength }\end{array}$ \\
\hline & $\alpha$ (angle in degrees) & $\alpha$ & $\begin{array}{l}\text { Measures the rate of } \\
\text { clot formation, reflects } \\
\text { fibrin rate of fibrin } \\
\text { build up and cross } \\
\text { linking }\end{array}$ \\
\hline Clot strength & $\begin{array}{l}\text { MA (maximum } \\
\text { amplitude) }\end{array}$ & $\begin{array}{l}\text { MCF (maximum clot } \\
\text { firmness) }\end{array}$ & $\begin{array}{l}\text { Represents the } \\
\text { ultimate strength of } \\
\text { the clot (platelets \& } \\
\text { fibrin) function of } \\
\text { maximum dynamic } \\
\text { properties of fibrin \& } \\
\text { platelet bonding via } \\
\text { GPIlb/IIla receptors }\end{array}$ \\
\hline Clot stability & $\begin{array}{l}\text { Ly30 (Lysis at } 30 \\
\text { minutes as ratio of } \\
\text { MA) }\end{array}$ & $\mathrm{CLI}$ (Clot lysis index) & $\begin{array}{l}\text { Measures rate of } \\
\text { amplitude reduction } \\
\text { from MA at } 30 \\
\text { minutes, detects } \\
\text { fibrinolysis }\end{array}$ \\
\hline
\end{tabular}

Fig. 1 Schematic of TEG/ROTEM parameters. TEG: $K$ time, coagulation time (20-mm clot); Ly30, lysis at 30 minutes; MA, maximum amplitude; $R$ time, reaction time (2-mm clot). ROTEM: CFT, clot formation time (20-mm clot); CLI, clot lysis index; CT, clotting time (2-mm clot); MCF, maximum clot firmness; ML, maximal lysis.

explanation as to why the R/CT does not appear to be sensitive to mild to moderate increases in PT/INR. ${ }^{29}$ Another factor is that TF expression on monocytes leads to shortening of the $\mathrm{R} / \mathrm{CT}$ as seen in some patients with cirrhosis, in sepsis, and following ischemia reperfusion injury. ${ }^{30}$ In cirrhosis, there is increased activation of the extrinsic pathway, indicated by elevated factor VIla levels, as a result of circulating microparticle TF activity. ${ }^{31}$ A pronounced prolongation of $\mathrm{R} / \mathrm{CT}$ is associated with clotting factor levels of $30 \%$ or less. In an animal model of hemodilution, the CT only starts to prolong once factor levels fall below 20 to $30 \%$, but corrects back to normal with administration of prothrombin complex concentrates (PCCs). ${ }^{32}$ The viscoelastic parameters, $\mathrm{R} / \mathrm{CT}$ and K/CFT (clot formation time), therefore may provide more comprehensive information on overall coagulation factor activity than CCTs.

Platelet count: Clot strength as assessed by the maximum amplitude (MA) or maximum clot firmness (MCF) is highly influenced by both fibrinogen levels and platelet count. ${ }^{33}$ The minimal platelet count for normal clot formation is not known, and is markedly affected by the fibrinogen level. In a study in patients with idiopathic thrombocytopenic purpura (ITP), it was found that the critical cutoff for platelet count was 310. ${ }^{9,34}$ There is rebalanced hemostasis in ITP with elevated levels of VWF and fibrinogen contributing to normalize the clot strength; consequently VET analysis is more helpful than a simple platelet count in determining treatment strategies. ${ }^{35}$ In CLD, in which fibrinogen levels are usually not raised, platelet count may have a more significant impact on changes in MA/MCF. ${ }^{14}$ Clot strength is a composite reflection of platelet-fibrinogen interaction, and adequate clot strength can be achieved even in the presence of a low platelet count if there is also high fibrinogen and/or VWF. The combination of both a low platelet count and a low fibrinogen always leads to a reduced MA/MCF and is strongly associated with an increased bleeding tendency. ${ }^{36}$ 
Fibrinogen: The Clauss method for the determination of fibrinogen is turbidimetric and depends on thrombininduced fibrin formation. Although the gold standard, it is influenced by multiple factors, including colloidal fluids and also some direct thrombin inhibitors. ${ }^{37,38}$ Both TEG and ROTEM have assays for monitoring fibrinogen levels. Platelet glycoprotein IIb/IIIa inhibitors (cytochalasin D in the ROTEM FIBTEM, and abciximab in the TEG functional fibrinogen assay) remove the platelet contribution to overall clot strength, and the resultant MA/MCF of the trace reflects the contribution from fibrinogen to clot formation. These tests correlate well with Clauss fibrinogen $(r=0.87)$ and can be used for making treatment intervention decisions. ${ }^{39} \mathrm{Col}-$ loidal fluids, particularly hydroxyl ethyl starches, interfere with fibrin polymerization, and this is reflected in lower functional fibrinogen. ${ }^{40}$ During LT, though there is good correlation with Clauss at baseline, after graft reperfusion when fibrinogen levels can fall below $100 \mathrm{mg} / \mathrm{dL}$, the correlation is not so good and could potentially result in overestimation. ${ }^{41}$

\section{Viscoelastic Tests and Chronic Liver Disease}

Because TEG and ROTEM are global tests providing a composite analysis that reflect function of plasma, blood cells, and platelets, they are increasingly viewed as an appropriate tool to investigate the coagulopathy of CLD. In agreement with the concept of rebalanced hemostasis, patients with cirrhosis often maintain normal global hemostasis as assessed by TEG. In a cohort of 273 patients with stable cirrhosis, it was found that mean and median TEG parameters were all within normal limits, although the MA decreased in proportion to the severity of thrombocytopenia and severity of liver disease. ${ }^{15}$ Tripodi et al compared ROTEM parameters between 58 healthy volunteers and 51 adult patients with cirrhosis. ${ }^{14}$ Abnormal ranges were defined as above the 95th percentile for CT and CFT or below the 5th percentile for MCF. ROC curves were constructed to identify patients with cirrhosis (true positives) from healthy individuals (true negatives). The CT did not distinguish between healthy and cirrhotic individuals and there was no correlation between PT and CT $(r=-0.264)$, and only $27 \%$ of patients with cirrhosis had any prolongation of CT despite the fact that PT was prolonged in all of them. Establishing a normal reference range for TEG/ROTEM values specifically for patients with liver disease is problematic because there will be significant variability between patients, dependent on both the underlying etiology and the stage of their liver disease.

The MA/MCF is a good discriminator of cirrhotic versus healthy individuals, and $76 \%$ of patients with cirrhosis had an abnormal ( $>2$ SD below normal) value. The MCF also correlates well with MELD score. Others have found that many patients with compensated cirrhosis have normal TEGs, ${ }^{42}$ and this supports the observation that overall hemostasis is relatively well preserved in these patients and that the compensatory mechanisms that occur in liver disease act to maintain a state of balanced hemostasis. Another study evaluated plasma TG and whole blood clot formation (ROTEM activated with $\mathrm{TF}$, with and without tissue plasminogen activator [tPA]) in 73 patients with all-cause cirrhosis (Child-Pugh $A=52, B=15, C=6$ ), and compared the results to 20 healthy controls. TG was increased with increasing severity of cirrhosis, while there was a progressive delay in clot formation rate and reduced clot strength as the severity of cirrhosis increased. The results indicated that cirrhotic patients have an overall procoagulant plasma milieu, but a reduced whole blood clot formation capacity with an apparently unaltered resistance to clot lysis. No significant differences were found for tPA-ROTEM parameters of clot degradation. ${ }^{43}$

The trigger for prophylactic platelet transfusion prior to invasive procedures, such as liver biopsy, is commonly set at a platelet count of $50 \times 10^{9} .{ }^{44}$ However, this does not take into account the multiple changes in the hemostatic profile of patients with liver disease, such as the elevated levels of VWF, or higher levels of fibrinogen that can occur in some patients with liver disease, and result in relatively normal clot firmness, despite thrombocytopenia. ${ }^{35,45}$ The increased levels of VWF seen in patients with cirrhosis means that simple platelet counts are not useful for predicting bleeding in patients with liver failure. A randomized controlled study in patients with cirrhosis of eltrombopag, a thrombopoietin receptor agonist, was terminated prematurely because of thrombotic complications in the treatment group. ${ }^{46}$ It was thought that elevated levels of VWF together with normalized platelet counts were the major contributing factor. ${ }^{47}$ The value of prophylactic platelet transfusion in preventing bleeding as a result of invasive procedures in cirrhotic patients has been largely been taken for granted, but without any confirmatory evidence. In a small observational study of 26 thrombocytopenic patients with cirrhosis, undergoing variceal ligation, who were given one standard adult dose platelet transfusion, the effects on TG and ROTEM were evaluated. Although there was a small increase in platelet count, from 39 (16-64) to 52 (19-91), there was no significant effect on TG, and only very modest improvements in ROTEM parameters, with none reaching normal values following platelet transfusion. ${ }^{48}$ The success of conservative transfusion policies followed in patients undergoing LT, where very much lower platelet counts are tolerated, unless there is active bleeding, calls the practice of prophylactic platelet transfusions for less invasive procedures into serious question. ${ }^{49}$ However, to date, no studies have directly tested whether global tests are useful in predicting procedural bleeding risk in patients with liver disease.

\section{Heparin-Like Effect and Chronic Liver Disease}

The native TEG is extremely sensitive to the presence of heparin and heparin-like substances. Coppell et al investigated the effects of unfractionated heparin (UFH), low-molecularweight heparin (LMWH), and danaparoid on native and heparinase TEGS. The difference between parameters in these two tests was able to differentiate between a range of low concentrations $(0.005-0.05 \mathrm{U} / \mathrm{mL})$ of these heparin-like substances and demonstrated a clear dose response, and in the case of UFH 
there was greater sensitivity than with anti-Xa activity. ${ }^{50}$ Though native TEG is undoubtedly the most sensitive method to detect low concentrations of heparin, kaolin-activated TEG assays have also been found to be a useful method to monitor and guide LMWH therapy in sick hospitalized patients, where comorbid conditions can impact on both the pharmacodynamics and pharmacokinetics of LMWH. ${ }^{51}$

In recent years there has been increasing interest in the detection and the significance of endogenous heparins. Under conditions of endothelial stress, such as surgery or sepsis, endogenous release of very small quantities of glycosaminoglycans (GAGS) may be detected systemically. ${ }^{52}$ Minor disturbances of the endothelial glycocalyx can lead to the selective cleavage of heparan and chondroitin sulfate side groups from the luminal layer of the glycocalyx. Where there is more significant damage to the vascular endothelium from ischemia or sepsis, systemic activation of coagulation is promoted, and it is thought that this shedding of GAGs into the circulation is an adaptive response to keep a progressively more procoagulant microvasculature open by means of endogenous heparinization. ${ }^{53}$ Five percent of patients with severe traumatic injury have evidence of acute endogenous heparinization on TEG, and given that their levels of syndecans 1 are also significantly increased, this can be mechanistically linked to endothelial glycocalyx degradation. ${ }^{54}$ When shed, the glycocalyx GAGs retain their anticoagulant activity and this is detectable by a prolonged $\mathrm{R}$ value on TEG analysis. These endogenous GAGs may represent an increased bleeding risk for some patients, ${ }^{55,56}$ and demonstration of their presence may provide clinically useful information. Bacterial infection in cirrhosis induces a heparin-like effect (HLE) detected by $\mathrm{TEG}^{56}$ and this reverses with antibiotics and resolution of the infection. Of 30 patients with infection, 28 had improved TEG parameters in the heparinase modified TEG, indicating a significant heparin effect, and this HLE disappeared after the infection resolved. HLE is associated with detectable anti-Xa activity ${ }^{57,58}$ and appears to differentiate patients at increased risk of variceal rebleeding. ${ }^{59}$ In contrast, none of the standard laboratory tests of hemostasis (INR, aPTT, and platelet count) differed between those that who rebled and those that did not. A further prospective observational study on patients with cirrhosis and acute variceal bleeding has confirmed the presence of endogenous heparinoids and their association with bleeding-related mortality. ${ }^{60} \mathrm{~A}$ transient HLE in systemic venous blood after transjugular intrahepatic portosystemic shunt (TIPS) has been reported, suggesting a high concentration of heparinoids in the portal venous system prior to TIPS placement. ${ }^{61}$

\section{Hypercoagulability and Chronic Liver Disease}

Hypercoagulability may have an important role in many aspects of liver disease, and intrahepatic microthrombi have been implicated in the progression of fibrosis. ${ }^{62}$ Portal vein thrombosis (PVT) is a common complication of liver cirrhosis, with an incidence of 10 to $25 \%$, with a greater tendency to thrombosis with more severe liver disease. ${ }^{63}$
Reduced portal blood flow and blood vessel damage may play an important role in the increased risk of PVT, ${ }^{64}$ but the hemostatic status may also be an important contributory factor. In cirrhosis, the ratio of the two most powerful proand anticoagulants in the plasma, factor VIII and protein C respectively, show a balance strongly in favor of factor VIII indicating hypercoagulability, ${ }^{65}$ and it is now appreciated that the risk of venous thrombosis is often greater in patients with cirrhosis than in those without liver disease. ${ }^{66}$ Indeed factor VIII levels rise as the severity of liver disease increases. Endotoxemia and subsequent TF expression on monocytes is also common in patients with cirrhosis or following LT. ${ }^{30}$

Ben-Ari et al evaluated hypercoagulability in patients with primary biliary cirrhosis (PBC) and primary sclerosing cholangitis (PSC) using TEG. Moreover, $28 \%$ of patients with PBC and $43 \%$ of patients with PSC were found to be hypercoagulable compared with only $5 \%$ of noncholestatic cirrhosis and none in healthy controls. ${ }^{8}$ In contrast, INR did not differ between patients with cholestatic versus noncholestatic cirrhosis. These observations may explain why patients with PSC and $\mathrm{PBC}$ have fewer bleeding complications and lower intraoperative transfusion requirements during LT. The relative hypercoagulability is ascribed to increased platelet reactivity and higher fibrinogen concentrations in patients with cholestatic liver disease. ${ }^{67}$

In a prospective, observational study in nonalcoholic fatty liver disease (NAFLD) using TEG, a significantly stronger clot development was found in patients compared with healthy controls (MA $58.3+-6.3$ vs. $52+-10 \mathrm{~mm} p=0.01$ ), and the platelet contribution to overall clot strength was higher in NAFLD patients with a trend to reduced inducible clot lysis $(p=0.03) .{ }^{68}$ It is recognized that patients with NAFLD are relatively prothrombotic and have an increased incidence of thrombosis. ${ }^{9}$ In a prospective study on 23 patients with obstructive jaundice, $80 \%$ were found to be hypercoagulable on TEG analysis (increased MA) and this was independent of prolonged PT times. A repeat TEG 3 weeks after a biliary drainage procedure showed all TEG parameters had return to normal range. ${ }^{69}$

The clinical implications of these findings have yet to be evaluated. However, emerging evidence suggests that hypercoagulability detected by VET puts patients in an "at-risk" group for both venous and arterial thrombotic events (TEs). ${ }^{12,70,71}$ A recent systematic review of 10 studies in surgical patients showed an increased MA to be the most important parameter to predict postoperative TE events. However, there was considerable variability as to which parameters were used to define hypercoagulability, and no study was adequately powered. Nevertheless, the vast majority of patients who had a TE event were hypercoagulable on one or more TEG parameters. ${ }^{72}$

\section{Viscoelastic Tests and Acute Liver Disease}

In more than 1,000 patients reviewed by The Acute Liver Failure Study Group (ALFSG), the mean INR was 3.8. ${ }^{73}$ Patients with ALF are assumed to have a bleeding diathesis based on the elevated INR; however, in reality, clinically significant bleeding is rare. As an ancillary project of the ALFSG, Stravitz 
et al prospectively studied 51 patients with ALI/ALF with kaolin initiated TEG. ${ }^{74}$ Despite a mean INR of 3.4 (range, 1.5-9.6), mean TEG parameters were within normal limits for the entire study population, and all five individual TEG parameters were completely normal in $63 \%$ of patients, suggesting that the dynamics of clot formation are generally well preserved. Moreover, $8 \%$ of patients were hypercoagulable. The TEG ( $R$ value) was significantly more sensitive than INR for predicting bleeding, and the INR was not significantly different in those who bled and those who did not. The MA was higher in ALF than ALI and correlated with increasing severity of liver injury. The preservation or even increase in MA in patients with ALI/ALF may be due to increased factor VIII levels, decreased ADAMTS13 activity, increased VWF, and increased levels of fibrinogen and/or platelets as acute phase reactants. As the severity of the systemic inflammatory response increased, there was a corresponding increase in MA. This important study demonstrates TEG parameters in ALF/ALI are generally well preserved, and potentially provides an explanation for why clinical bleeding is rare despite the elevated INR. The authors concluded that INR, although a valid indicator of prognosis, is not a good guide for administration of procoagulant therapy.

In another prospective study of 20 patients admitted to ICU with ALF, coagulation analysis was performed on admission and at 48 hours. CCT suggested a markedly hypocoagulable state with a significantly raised INR (mean 4.3); however, TEG values were hypocoagulable in only $20 \%$ of patients, whereas $45 \%$ had normal and $35 \%$ had hypercoagulable profiles. All patients with hypocoagulable TEGs had platelet counts of less than $100,000 .^{75}$ The fact that $80 \%$ of these patients with ALF had normal, or even hypercoagulable TEG profiles is evidence of the rebalancing of hemostasis, with the fall in procoagulant levels counterbalanced by low levels of anticoagulant proteins, together with significant increases in VWF and factor VIII.

\section{Endogenous Heparin and Acute Liver Failure}

An HLE is commonly seen in ALF. ${ }^{76,77}$ This HLE is thought to be due to the release of endogenous heparinoids and reflects the vascular endothelial injury inherent with acute liver injury. In ALF, the R time is significantly increased in the presence of infection, renal failure, and in those with bleeding complications. ${ }^{74}$ In an observational study comparing TEG parameters in ALF to those in cirrhosis, Senzolo et al found that R and $\mathrm{K}$ times and $\alpha$ angle on native TEGs were significantly more hypocoagulable in ALF patients undergoing orthotopic liver transplantation (OLT) compared with control stable patients with cirrhosis. These TEG changes were ascribed to endogenous heparinoids as heparinase reversed these differences. ${ }^{78}$ Heparinase-modified TEG should be considered as a useful adjunct in the assessment of coagulopathy in ALF.

\section{Liver Transplantation}

Historically liver transplantation (LT) was accompanied by substantial blood loss; however, improvements to all aspects of the process, from graft preservation through to surgical techniques and anesthetic management, have led to an increasing number of patients being able to undergo LT without the need for transfusion of red blood cells or blood products, ${ }^{79}$ although there continues to be a small, but significant proportion of patients that will require massive transfusion. Marked variations in inter-institutional transfusion requirements for LT still persist. ${ }^{80}$ Varying transfusion thresholds, particularly in relation to the use of FFP, differences in the way coagulation is (or is not) monitored, the use of cell salvage, fluid management strategies, and use of antifibrinolytic therapy, all lead to wide variations in blood product use. ${ }^{25,81}$ Preoperative hemoglobin is the most significant predictor of the need for red cell transfusion. ${ }^{82}$ Fluid management is very important, and restrictive fluid administration in the dissection phase can minimize hemodilution, preserving hematocrit and clotting factor levels, as well as limiting rises in splanchnic and portal pressure that will exacerbate bleeding. The etiology of liver failure is an independent parameter for the prediction of massive blood loss. ${ }^{83}$ Preoperative PT/INR is not predictive of the need for transfusion. ${ }^{84}$ It is of note that transplant units that report the lowest rate of blood and blood product use, have adopted aggressive fluid restriction, tolerance of low hemoglobin thresholds, and treat only when there is active bleeding, avoiding prophylactic therapy. ${ }^{85}$ There is an obvious need to develop consensus guidelines for transfusion practice in LT and to determine which method of coagulation monitoring and which transfusion thresholds are optimal. ${ }^{86}$ The inverse relationship between the number of units of RBC transfused intraoperatively, and patient survival is well known. ${ }^{87}$ The concepts of Patient Blood Management programs, with a multimodal approach to limiting inappropriate and unnecessary transfusions, should be advanced for all surgical procedures, including LT, as this leads to reduced exposure to allogeneic products, with their immunomodulatory and other adverse consequences, and ultimately reduces hospital costs. ${ }^{88}$

\section{Viscoelastic Tests and Coagulation Management in Liver Transplantation}

Coagulation monitoring with TEG/ROTEM can reduce overall transfusion requirements as empirical therapy is eliminated and specific management of coagulation defects is instituted at an early stage. ${ }^{13,89}$ TEG-guided transfusion algorithms to treat coagulopathy in OLT were first introduced in the early 1980s by Kang at the University of Pittsburgh, who showed that using an algorithm based on TEG, transfusion requirements were reduced by $30 \%$ compared with an historical cohort. ${ }^{13}$ In the context of LT, VETs are particularly useful for detecting the presence of systemic fibrinolysis, and also to detect poor clot strength that is often the result of low fibrinogen levels. ${ }^{90}$ The use of goal-orientated algorithms based on VET facilitate targeted transfusion therapies with specific hemostatic agents and avoids the empirical administration of multiple components with potentially hazardous effects, and are recommended (grade $1 \mathrm{C}$ ) in recent guidelines for the management of severe bleeding. ${ }^{91}$ The short turn 
around times of VET (10-20 minutes) are important for guiding therapy and preventing inappropriate transfusion during surgery and on the ITU. ${ }^{92}$ The use of algorithms, although reducing transfusion requirements compared with historical cohorts, often leads to changes in the type and amount of hemostatic support given, with many European units using increasing amounts of factor concentrates, including PCCs and fibrinogen concentrates. ${ }^{90,93}$

Monitoring coagulation with basic VETs, without assessment of fibrinogen (FIBTEM or TEG functional fibrinogen) can lead to increased transfusion of platelets to increase the MA/ MCF. ${ }^{94}$ Using VETs to specifically assess fibrinogen levels can avoid platelet transfusion, where goal-directed substitution of fibrinogen is more appropriate. This is especially important in LT as platelet transfusion is associated with significant reductions in one year survival. ${ }^{95}$ Although there does not appear to be increased risk of thromboembolic events as a result of using fibrinogen concentrates, there remains some concern about the safety profile of PCCs, as in the setting of trauma, it has been demonstrated that in patients receiving PCC, compared with those that did not, endogenous thrombin potential is increased for several days post operatively, and also that antithrombin (AT) levels remain low, implying a potential prothrombotic state not reflected by standard coagulation tests. ${ }^{96}$ The results of the PROTON study, a randomized controlled study of PCC in LT are awaited with interest. ${ }^{97}$ There may well be a place for PCC in treating severe clotting factor deficiency, such as in dilutional coagulopathy, where there is marked prolongation of the $\mathrm{R} / \mathrm{CT}$ and loss of the normal TG profile on VET (increased K/CFT and decreased $\alpha$ angle), but this needs to be validated in future trials. It took several years before the increased risk of arterial TE events associated with the use of recombinant factor VIIa (rFVIIa) was recognized, another drug that acts by enhancing TG. ${ }^{98}$ It is now recommended that rFVIIa should only be used as rescue therapy, ${ }^{91}$ and it is of note that where VET monitoring is routine, the use of rFVIIa has been virtually eliminated, suggesting that VET coagulation monitoring results in earlier and more effective hemostatic inteventions. ${ }^{99}$

Although there are many reports of the success of VET monitoring in reducing transfusion requirements in LT, this must be seen in the context that the majority of these studies generally compare these results with historical cohorts, and also in many cases, there was a relatively high baseline transfusion rate. ${ }^{89,100,101} \mathrm{~A}$ more recent prospective study of 60 LT patients, with and without ROTEM monitoring, did not demonstrate any significant differences, but overall transfusion was low, with a significant number of patients receiving no transfusion at all. ${ }^{102}$ It is difficult to extrapolate the results of earlier studies to the current situation, as bleeding and transfusion management continues to evolve with many interrelated factors leading to lower transfusion rates. It is clear, however, that the implementation of dedicated liver transplant anesthesia teams and the use of transfusion protocols lead to improved transfusion practice. ${ }^{103}$ The transfusion trigger thresholds described for VET have not been validated, and values may need to be substantially outside normal ranges before intervention is indicated. ${ }^{104} \mathrm{~A}$ small proportion of patients undergoing LT will inevitably have massive blood loss, and there is no doubt that VET can be useful in these circumstances to facilitate goal-directed therapy and assess the efficacy of any treatment intervention. In addition, they provide important information on fibrinolysis, HLE, and hypercoagulability, which is not available from CCT. Finally, the fact that up to $60 \%$ of VET traces are within normal ranges at baseline, despite hypocoagulable CCTs, is commensurate with the concept of "rebalanced" hemostasis, and the fact that an increasing number of patients are able to undergo this major surgery without the need for blood or blood products.

\section{Fibrinolysis and Orthotopic Liver Transplant}

It is known that enhanced fibrinolytic activity can occur at any point during LT, but particularly during the anhepatic period, due to lack of tPA clearance, ${ }^{105}$ and that this is followed immediately after reperfusion by a dramatic increase in tPA, which can be associated with explosive primary hyperfibrinolysis, ${ }^{106}$ leading some patients to develop diffuse uncontrolled bleeding. In the presence of good graft function, hyperfibrinolysis after reperfusion is usually self-limiting and does not require treatment, but in the presence of a poorly functional or marginal graft it may persist, and will require treatment with antifibrinolytic drugs such as tranexamic acid (1-2 g) ${ }^{107}$ Fibrinolysis is rarely seen in ALF due to the high levels of PAI-1. Routine use of prophylactic antifibrinolytic agents was common in the early history of LT, as the mortality associated with massive blood loss was high, and any potential risk associated with the use of antifibrinolytics was small in comparison. The risk-benefit balance is altered now that massive bleeding is less frequent, and there is a move away from prophylactic therapy toward selective (high-risk patients) or treatment only. Prediction is difficult as hyperfibrinolysis-induced bleeding may become most pronounced in the postreperfusion stage of the operation and depends to a great extent on the quality of the donor liver, which is not reflected by the preoperative condition of the recipient. ${ }^{108}$ Treatment with antifibrinolytic therapy is recommended when there is evidence of microvascular ooze and/or documented fibrinolysis (CLI >15) on TEG/ROTEM. The timing and degree of fibrinolysis is relevant, and lesser degrees of fibrinolysis occurring after reperfusion may resolve spontaneously. ${ }^{109,110}$

\section{Heparin Effect and Orthotopic Liver Transplant}

The appearance of a marked heparin effect on TEG at reperfusion was first described by Kang, ${ }^{111}$ and is due to both exogenous heparin administered to the donor, and also release of endogenous heparinoids from the vascular endothelium, indicative of glycocalyx injury, and release of heparinoids from activated macrophages due to ischemia/ reperfusion injury. ${ }^{112}$ It does not appear to contribute significantly to bleeding risk and is usually a temporary phenomenon unless graft function is poor. ${ }^{113}$ Reversal with protamine is rarely indicated. Native TEG is extremely sensitive to 
heparin and as endogenous heparin can be detected in some patients even prior to reperfusion, ${ }^{55}$ it is recommended that heparinase-modified TEG be run in parallel with native TEG during LT. With the more activated Kaolin TEG and INTEM, it is unusual to identify a significant heparin effect, except at reperfusion, and an additional heparinase or HEPTEM test is helpful at this stage to distinguish between a coagulation factor deficiency and heparin-producing prolongation of the $\mathrm{R} / \mathrm{CT}$.

\section{Hypercoagulability and Orthotopic Liver Transplant}

CCTs give no information about where the balance of coagulation lies, and may indicate hypocoagulability, when global tests indicate an enhance coagulation capacity or hypercoagulability. ${ }^{114}$ It is conceivable that such patients may come to harm if hypercoagulability is unrecognized and consequently inappropriately managed. A retrospective review of TEG parameters and CCT in 100 LT patients found that evidence of hypercoagulability is relatively common in these patients, and that an elevated INR in no way excludes this possibility. ${ }^{115}$ Hypercoagulability on TEG/ROTEM can be differentiated into either plasmatic (shortened $\mathrm{R} / \mathrm{CT}$ ) or due to increased clot strength (MA/MCF), or a combination of both. Plasmatic hypercoagulability is more common in patients with alcoholic and viral cirrhosis, and is seen most often during the anhepatic phase (28\%), and may be indicative of TF expression due to endotoxemia. ${ }^{116}$ Patients with PSC and PBC have a significantly increased prevalence of hypercoagulability at baseline as determined by the MA/MCF. Many intraoperative factors can contribute to the persistence of, or the de novo development of hypercoagulability, including vascular stasis, coagulation activation by endotoxin, and local inflammation of the graft organ by ischemia reperfusion injury. The sudden development of intracardiac and/or pulmonary emboli is a rare, but well recognized, and potentially lethal complication of LT. A systematic review found an incidence of $1 \%$, with a mortality of $68 \%{ }^{117} \mathrm{~A}$ retrospective review of more than 900 OLT cases found an incidence of intracardiac thrombi of $1.9 \%$, with the majority occurring around the time of reperfusion. ${ }^{118}$ Because the anticoagulant mechanisms are compromised in patients with liver disease, excessive clot formation can easily occur when coagulation is triggered; however, because the fibrinolytic system is also strongly activated following reperfusion, these initial clots are usually rapidly removed. There appears to be some association of intracardiac thrombi with hypercoagulable TEG profiles. In a review of 27 case reports of TE in OLT, the TEG was hypercoagulable in more than $70 \%$ of cases, whereas conventional tests were all hypocoagulable. ${ }^{119}$ The clinical significance of detecting hypercoagulability during LT is currently unknown; however, it would seem unwise to give blood products or other prohaemostatic therapy when it is present.

\section{Conclusion}

CCTs are not able to discriminate between hypo- and hypercoagulability, nor are they able to reliably predict the risk of bleeding in patients with liver dysfunction. Coagulation analysis with TEG and ROTEM has corroborated the concept of rebalanced hemostasis in liver disease proposed by Tripodi and Mannucci ${ }^{120}$ and Lisman and Porte. ${ }^{4}$ The majority of stable patients with CLD have normal VET, and this calls into serious question the practice of giving prophylactic treatment purely to correct a prolonged INR value or a moderately reduced platelet count. VET also gives us important additional information, including the role of the acute phase reaction in augmenting clot strength, which can compensate for low platelet counts and can result in normal or even hypercoagulable parameters of clot tensile strength. In addition, identification of endogenous heparin release (HLE) has demonstrated the important link between infection, ischemia-reperfusion injury, and impaired hemostasis.

The summative information provided by VET has helped elucidate some of the complex hemostatic changes that occur in liver disease, and it is highly likely that they will be used in future outcome studies to help determine and stratify bleeding risk, and also to help diagnose underlying prothrombotic states in patients with liver disease.

\section{References}

1 Mannucci PM. Abnormal hemostasis tests and bleeding in chronic liver disease: are they related? No. J Thromb Haemost 2006; 4(4):721-723

2 Tripodi A, Mannucci PM. Abnormalities of hemostasis in chronic liver disease: reappraisal of their clinical significance and need for clinical and laboratory research. J Hepatol 2007;46(4):727-733

3 Caldwell SH, Hoffman M, Lisman T, et al; Coagulation in Liver Disease Group. Coagulation disorders and hemostasis in liver disease: pathophysiology and critical assessment of current management. Hepatology 2006;44(4):1039-1046

4 Lisman T, Porte RJ. Rebalanced hemostasis in patients with liver disease: evidence and clinical consequences. Blood 2010;116(6): 878-885

5 Tripodi A, Salerno F, Chantarangkul V, et al. Evidence of normal thrombin generation in cirrhosis despite abnormal conventional coagulation tests. Hepatology 2005;41(3):553-558

6 Søgaard KK, Horváth-Puhó E, Grønbaek H, Jepsen P, Vilstrup H, Sørensen HT. Risk of venous thromboembolism in patients with liver disease: a nationwide population-based case-control study. Am J Gastroenterol 2009;104(1):96-101

7 Massicotte L, Beaulieu D, Thibeault L, et al. Coagulation defects do not predict blood product requirements during liver transplantation. Transplantation 2008;85(7):956-962

8 Ben-Ari Z, Panagou M, Patch D, et al. Hypercoagulability in patients with primary biliary cirrhosis and primary sclerosing cholangitis evaluated by thrombelastography. J Hepatol 1997; 26(3):554-559

9 Kargili A, Cipil H, Karakurt F, et al. Hemostatic alterations in fatty liver disease. Blood Coagul Fibrinolysis 2010;21(4):325-327

10 Shore-Lesserson L, Manspeizer HE, DePerio M, Francis S, VelaCantos F, Ergin MA. Thromboelastography-guided transfusion algorithm reduces transfusions in complex cardiac surgery. Anesth Analg 1999;88(2):312-319 
11 Schöchl H, Frietsch T, Pavelka M, Jámbor C. Hyperfibrinolysis after major trauma: differential diagnosis of lysis patterns and prognostic value of thrombelastometry. J Trauma 2009;67(1): 125-131

12 Kashuk JL, Moore EE, Sabel A, et al. Rapid thrombelastography (rTEG) identifies hypercoagulability and predicts thromboembolic events in surgical patients. Surgery 2009;146(4):764-772, discussion $772-774$

13 Kang YG, Martin DJ, Marquez J, et al. Intraoperative changes in blood coagulation and thrombelastographic monitoring in liver transplantation. Anesth Analg 1985;64(9):888-896

14 Tripodi A, Primignani M, Chantarangkul V, et al. The coagulopathy of cirrhosis assessed by thromboelastometry and its correlation with conventional coagulation parameters. Thromb Res 2009; 124(1):132-136

15 Stravitz RT. Potential applications of thromboelastography in patients with acute and chronic liver disease. Gastroenterol Hepatol (N Y) 2012;8(8):513-520

16 Tripodi A, Chantarangkul V, Mannucci PM. Acquired coagulation disorders: revisited using global coagulation/anticoagulation testing. Br J Haematol 2009;147(1):77-82

17 Mann KG, Butenas S, Brummel K. The dynamics of thrombin formation. Arterioscler Thromb Vasc Biol 2003;23(1):17-25

18 Kamal AH, Tefferi A, Pruthi RK. How to interpret and pursue an abnormal prothrombin time, activated partial thromboplastin time, and bleeding time in adults. Mayo Clin Proc 2007;82(7): 864-873

19 Roberts HR, Monroe DM, Escobar MA. Current concepts of hemostasis: implications for therapy. Anesthesiology 2004; 100(3):722-730

20 Hoffman M, Monroe DM III. A cell-based model of hemostasis. Thromb Haemost 2001;85(6):958-965

21 Wolberg AS. Thrombin generation and fibrin clot structure. Blood Rev 2007;21(3):131-142

22 Hartert H. [Not Available]. Klin Wochenschr 1948;26(37-38): 577-583

23 Ganter MT, Hofer CK. Coagulation monitoring: current techniques and clinical use of viscoelastic point-of-care coagulation devices. Anesth Analg 2008;106(5):1366-1375

24 Whiting D, DiNardo JA. TEG and ROTEM: technology and clinical applications. Am J Hematol 2014;89(2):228-232

25 Coakley M, Reddy K, Mackie I, Mallett S. Transfusion triggers in orthotopic liver transplantation: a comparison of the thromboelastometry analyzer, the thromboelastogram, and conventional coagulation tests. J Cardiothorac Vasc Anesth 2006;20(4):548-553

26 Kitchen DP, Kitchen S, Jennings I, Woods T, Walker I. Quality assurance and quality control of thrombelastography and rotational Thromboelastometry: the UK NEQAS for blood coagulation experience. Semin Thromb Hemost 2010;36(7):757-763

27 Karon BS. Why is everyone so excited about thromboelastrography (TEG)? Clin Chim Acta 2014;436:143-148

28 Roullet S, Pillot J, Freyburger G, et al. Rotation thromboelastometry detects thrombocytopenia and hypofibrinogenaemia during orthotopic liver transplantation. Br J Anaesth 2010;104(4): 422-428

29 Nascimento B, Al Mahoos M, Callum J, et al. Vitamin K-dependent coagulation factor deficiency in trauma: a comparative analysis between international normalized ratio and thromboelastography. Transfusion 2012;52(1):7-13

30 Esch JS, Jurk K, Knoefel WT, et al. Platelet activation and increased tissue factor expression on monocytes in reperfusion injury following orthotopic liver transplantation. Platelets 2010;21(5): 348-359

31 Rautou PE, Vion AC, Luyendyk JP, Mackman N. Circulating microparticle tissue factor activity is increased in patients with cirrhosis. Hepatology 2014;60(5):1793-1795

32 Fries D, Haas T, Klingler A, et al. Efficacy of fibrinogen and prothrombin complex concentrate used to reverse dilutional coagulopathy-a porcine model. Br J Anaesth 2006;97(4): 460-467

33 Alexander DC, Butt WW, Best JD, Donath SM, Monagle PT, Shekerdemian LS. Correlation of thromboelastography with standard tests of anticoagulation in paediatric patients receiving extracorporeal life support. Thromb Res 2010;125(5):387-392

34 Gunduz E, Akay OM, Bal C, Gulbas Z. Can thrombelastography be a new tool to assess bleeding risk in patients with idiopathic thrombocytopenic purpura? Platelets 2011;22(7):516-520

35 Kim WH, Park JB, Jung CW, Kim GS. Rebalanced hemostasis in patients with idiopathic thrombocytopenic purpura. Platelets 2015;26(1):38-42

36 Görlinger K, Dirkmann D, Hanke AA, et al. First-line therapy with coagulation factor concentrates combined with point-of-care coagulation testing is associated with decreased allogeneic blood transfusion in cardiovascular surgery: a retrospective, singlecenter cohort study. Anesthesiology 2011;115(6):1179-1191

37 Fenger-Eriksen C, Moore GW, Rangarajan S, Ingerslev J, Sørensen B. Fibrinogen estimates are influenced by methods of measurement and hemodilution with colloid plasma expanders. Transfusion 2010;50(12):2571-2576

38 Molinaro RJ, Szlam F, Levy JH, Fantz CR, Tanaka KA. Low plasma fibrinogen levels with the Clauss method during anticoagulation with bivalirudin. Anesthesiology 2008;109(1):160-161

39 Harr JN, Moore EE, Ghasabyan A, et al. Functional fibrinogen assay indicates that fibrinogen is critical in correcting abnormal clot strength following trauma. Shock 2013;39(1):45-49

40 Haase N, Ostrowski SR, Wetterslev J, et al. Thromboelastography in patients with severe sepsis: a prospective cohort study. Intensive Care Med 2015;41(1):77-85

41 Yang Lu S, Tanaka KA, Abuelkasem E, Planinsic RM, Sakai T. Clinical applicability of rapid thrombelastography and functional fibrinogen thrombelastography to adult liver transplantation. Liver Transpl 2014;20(9):1097-1105

42 Thalheimer U, Triantos CK, Samonakis DN, et al. A comparison of kaolin-activated versus nonkaolin-activated thromboelastography in native and citrated blood. Blood Coagul Fibrinolysis 2008; 19(6):495-501

43 Kleinegris MC, Bos MH, Roest M, et al. Cirrhosis patients have a coagulopathy that is associated with decreased clot formation capacity. J Thromb Haemost 2014;12(10):1647-1657

44 Rockey DC, Caldwell SH, Goodman ZD, Nelson RC, Smith AD; American Association for the Study of Liver Diseases. Liver biopsy. Hepatology 2009;49(3):1017-1044

45 Herbstreit F, Winter EM, Peters J, Hartmann M. Monitoring of haemostasis in liver transplantation: comparison of laboratory based and point of care tests. Anaesthesia 2010;65(1): 44-49

46 Afdhal NH, Giannini EG, Tayyab G, et al; ELEVATE Study Group. Eltrombopag before procedures in patients with cirrhosis and thrombocytopenia. N Engl J Med 2012;367(8):716-724

47 Lisman T, Porte RJ. Eltrombopag before procedures in patients with cirrhosis and thrombocytopenia. N Engl J Med 2012; 367(21):2055-2056

48 Tripodi A, Primignani M, Chantarangkul V, et al. Global hemostasis tests in patients with cirrhosis before and after prophylactic platelet transfusion. Liver Int 2013;33(3):362-367

49 Weeder PD, Porte RJ, Lisman T. Hemostasis in liver disease: implications of new concepts for perioperative management. Transfus Med Rev 2014;28(3):107-113

50 Coppell JA, Thalheimer U, Zambruni A, et al. The effects of unfractionated heparin, low molecular weight heparin and danaparoid on the thromboelastogram (TEG): an in-vitro comparison of standard and heparinase-modified TEGs with conventional coagulation assays. Blood Coagul Fibrinolysis 2006;17(2):97-104

51 White H, Sosnowski K, Bird R, Jones M, Solano C. The utility of thromboelastography in monitoring low molecular weight 
heparin therapy in the coronary care unit. Blood Coagul Fibrinolysis 2012;23(4):304-310

52 McKee RF, Hodson S, Dawes J, Garden OJ, Carter DC. Plasma concentrations of endogenous heparinoids in portal hypertension. Gut 1992;33(11):1549-1552

53 Nelson A, Berkestedt I, Schmidtchen A, Ljunggren L, Bodelsson M. Increased levels of glycosaminoglycans during septic shock: relation to mortality and the antibacterial actions of plasma. Shock 2008;30(6):623-627

54 Ostrowski SR, Johansson PI. Endothelial glycocalyx degradation induces endogenous heparinization in patients with severe injury and early traumatic coagulopathy. J Trauma Acute Care Surg 2012;73(1):60-66

55 Kettner SC, Gonano C, Seebach F, et al. Endogenous heparin-like substances significantly impair coagulation in patients undergoing orthotopic liver transplantation. Anesth Analg 1998;86(4): 691-695

56 Montalto P, Vlachogiannakos J, Cox DJ, Pastacaldi S, Patch D, Burroughs AK. Bacterial infection in cirrhosis impairs coagulation by a heparin effect: a prospective study. J Hepatol 2002;37(4): 463-470

57 Papatheodoridis GV, Patch D, Webster GJ, Brooker J, Barnes E, Burroughs AK. Infection and hemostasis in decompensated cirrhosis: a prospective study using thrombelastography. Hepatology 1999;29(4):1085-1090

58 Thalheimer U, Triantos C, Samonakis D, et al. Endogenous heparinoids in acute variceal bleeding. Gut 2005;54(2):310-311

59 Chau TN, Chan YW, Patch D, Tokunaga S, Greenslade L, Burroughs AK. Thrombelastographic changes and early rebleeding in cirrhotic patients with variceal bleeding. Gut 1998;43(2):267-271

60 Triantos C, Louvros E, Kalafateli M, et al. Endogenous heparinoids detected by anti-Xa activity are present in blood during acute variceal bleeding in cirrhosis. A prospective study. J Gastrointestin Liver Dis 2014;23(2):187-194

61 Thalheimer U, Triantos C, Samonakis D, Patch D, Burroughs AK. Heparin effect on thromboelastography after transjugular intrahepatic portosystemic shunt procedure. Scand J Gastroenterol 2009;44(12):1463-1470

62 Northup PG. Hypercoagulation in liver disease. Clin Liver Dis 2009;13(1):109-116

63 Tsochatzis EA, Senzolo M, Germani G, Gatt A, Burroughs AK. Systematic review: portal vein thrombosis in cirrhosis. Aliment Pharmacol Ther 2010;31(3):366-374

64 Hoekstra J, Janssen HL. Vascular liver disorders (II): portal vein thrombosis. Neth J Med 2009;67(2):46-53

65 Tripodi A, Primignani M, Chantarangkul V, et al. An imbalance of pro- vs anti-coagulation factors in plasma from patients with cirrhosis. Gastroenterology 2009;137(6):2105-2111

66 Tripodi A, Anstee QM, Sogaard KK, Primignani M, Valla DC. Hypercoagulability in cirrhosis: causes and consequences. J Thromb Haemost 2011;9(9):1713-1723

67 Pihusch R, Rank A, Göhring P, Pihusch M, Hiller E, Beuers U. Platelet function rather than plasmatic coagulation explains hypercoagulable state in cholestatic liver disease. J Hepatol 2002;37(5):548-555

68 Hickman IJ, Sullivan CM, Flight S, et al. Altered clot kinetics in patients with non-alcoholic fatty liver disease. Ann Hepatol 2009; 8(4):331-338

69 Cakir T, Cingi A, Yeğen C. Coagulation dynamics and platelet functions in obstructive jaundiced patients. J Gastroenterol Hepatol 2009;24(5):748-751

70 McCrath DJ, Cerboni E, Frumento RJ, Hirsh AL, Bennett-Guerrero E. Thromboelastography maximum amplitude predicts postoperative thrombotic complications including myocardial infarction. Anesth Analg 2005;100(6):1576-1583

71 Toukh M, Siemens DR, Black A, et al. Thromboelastography identifies hypercoagulablilty and predicts thromboembolic com- plications in patients with prostate cancer. Thromb Res 2014; 133(1):88-95

72 Dai Y, Lee A, Critchley LAH, White PF. Does thromboelastography predict postoperative thromboembolic events? A systematic review of the literature. Anesth Analg 2009;108(3):734-742

73 Munoz SJ, Rajender Reddy K, Lee W; Acute Liver Failure Study Group. The coagulopathy of acute liver failure and implications for intracranial pressure monitoring. Neurocrit Care 2008;9(1): 103-107

74 Stravitz RT, Lisman T, Luketic VA, et al. Minimal effects of acute liver injury/acute liver failure on hemostasis as assessed by thromboelastography. J Hepatol 2012;56(1):129-136

75 Agarwal B, Wright G, Gatt A, et al. Evaluation of coagulation abnormalities in acute liver failure. J Hepatol 2012;57(4): 780-786

76 Herriman DJ, Mallett S. A comparison of baseline international normalised ratio (INR) and thromboelastography (TEG) R times, and transfusion requirements for patients with fulminant hepatic failure undergoing orthotopic liver transplant (OLT). Liver Transpl 2011;17(6):S120

77 Agarwal S, Senzolo M, Melikian C, Burroughs A, Mallett SV. The prevalence of a heparin-like effect shown on the thromboelastograph in patients undergoing liver transplantation. Liver Transpl 2008;14(6):855-860

78 Senzolo M, Riddell A, Tuddenham E, Burroughs AK. Endogenous heparinoids contribute to coagulopathy in patients with liver disease. J Hepatol 2008;48(2):371-372, author reply 372-373

79 Massicotte L, Lenis S, Thibeault L, Sassine MP, Seal RF, Roy A. Reduction of blood product transfusions during liver transplantation. Can J Anaesth 2005;52(5):545-546

80 Ozier Y, Pessione F, Samain E, Courtois F; French Study Group on Blood Transfusion in Liver Transplantation. Institutional variability in transfusion practice for liver transplantation. Anesth Analg 2003;97(3):671-679

81 Schumann R. Intraoperative resource utilization in anesthesia for liver transplantation in the United States: a survey. Anesth Analg 2003;97(1):21-28 table of contents.

82 Steib A, Freys G, Lehmann C, Meyer C, Mahoudeau G. Intraoperative blood losses and transfusion requirements during adult liver transplantation remain difficult to predict. Can J Anaesth 2001;48(11):1075-1079

83 McCluskey SA, Karkouti K, Wijeysundera DN, et al. Derivation of a risk index for the prediction of massive blood transfusion in liver transplantation. Liver Transpl 2006;12(11):1584-1593

84 Massicotte L, Beaulieu D, Roy JD, et al. MELD score and blood product requirements during liver transplantation: no link. Transplantation 2009;87(11):1689-1694

85 Massicotte L, Denault AY, Thibeault L, Hevesi Z, Nozza A, Roy A. Relationship between conventional coagulation tests and bleeding for 600 consecutive liver transplantations. Transplantation 2014;98(2):e13-e15

86 Lopez-Plaza I. Transfusion guidelines and liver transplantation: time for consensus. Liver Transpl 2007;13(12):1630-1632

87 Massicotte L, Sassine MP, Lenis S, Seal RF, Roy A. Survival rate changes with transfusion of blood products during liver transplantation. Can J Anaesth 2005;52(2):148-155

88 Trentino KM, Farmer SL, Swain SG, et al. Increased hospital costs associated with red blood cell transfusion. Transfusion 2014

89 Trzebicki J, Flakiewicz E, Kosieradzki M, et al. The use of thromboelastometry in the assessment of hemostasis during orthotopic liver transplantation reduces the demand for blood products. Ann Transplant 2010;15(3):19-24

90 Gorlinger K, Dirkmann D, Muller-Beissenhirtz H, Paul A, Hartmann M, Saner F. Thromboelastometry-based perioperative coagulation management in visceral surgery and liver transplantation: experience of 10 tears and 1105 LTX. Liver Transpl 2010;16(6):S86 
91 Kozek-Langenecker SA, Afshari A, Albaladejo P, et al. Management of severe perioperative bleeding: guidelines from the European Society of Anaesthesiology. Eur J Anaesthesiol 2013;30(6): 270-382

92 Haas T, Spielmann N, Mauch J, et al. Comparison of thromboelastometry $\left(\right.$ ROTEM $\left.{ }^{\circledR}\right)$ with standard plasmatic coagulation testing in paediatric surgery. Br J Anaesth 2012;108(1):36-41

93 Kirchner C, Dirkmann D, Treckmann JW, et al. Coagulation management with factor concentrates in liver transplantation: a singlecenter experience. Transfusion 2014;54(10 Pt 2):2760-2768

94 Larsen OH, Fenger-Eriksen C, Christiansen K, Ingerslev J, Sørensen B. Diagnostic performance and therapeutic consequence of thromboelastometry activated by kaolin versus a panel of specific reagents. Anesthesiology 2011;115(2):294-302

95 Pereboom ITA, de Boer MT, Haagsma EB, Hendriks HGD, Lisman T, Porte RJ. Platelet transfusion during liver transplantation is associated with increased postoperative mortality due to acute lung injury. Anesth Analg 2009;108(4):1083-1091

96 Schöchl H, Voelckel W, Maegele M, Kirchmair L, Schlimp CJ. Endogenous thrombin potential following hemostatic therapy with 4-factor prothrombin complex concentrate: a 7-day observational study of trauma patients. Crit Care 2014;18(4):R147

97 Arshad F, Ickx B, van Beem RT, et al. Prothrombin complex concentrate in the reduction of blood loss during orthotopic liver transplantation: PROTON-trial. BMC Surg 2013;13:22

98 Mannucci PM, Franchini M. Recombinant factor VIla as haemostatic therapy in advanced liver disease. Blood Transfus 2013; 11(4):487-490

99 Ferraris VA, Brown JR, Despotis GJ, et al; Society of Thoracic Surgeons Blood Conservation Guideline Task Force; Society of Cardiovascular Anesthesiologists Special Task Force on Blood Transfusion; International Consortium for Evidence Based Perfusion. 2011 update to the Society of Thoracic Surgeons and the Society of Cardiovascular Anesthesiologists blood conservation clinical practice guidelines. Ann Thorac Surg 2011;91(3):944-982

100 Noval-Padillo JA, León-Justel A, Mellado-Miras P, et al. Introduction of fibrinogen in the treatment of hemostatic disorders during orthotopic liver transplantation: implications in the use of allogenic blood. Transplant Proc 2010;42(8):2973-2974

101 Wang SC, Shieh JF, Chang KY, et al. Thromboelastography-guided transfusion decreases intraoperative blood transfusion during orthotopic liver transplantation: randomized clinical trial. Transplant Proc 2010;42(7):2590-2593

102 Roullet S, Freyburger G, Cruc M, et al. Management of bleeding and transfusion during liver transplantation before and after the introduction of a ROTEM -based algorithm. Liver Transpl 2014

103 Hevesi ZG, Lopukhin SY, Mezrich JD, Andrei AC, Lee M. Designated liver transplant anesthesia team reduces blood transfusion, need for mechanical ventilation, and duration of intensive care. Liver Transpl 2009;15(5):460-465
104 Wang SC, Lin HT, Chang KY, et al. Use of higher thromboelastogram transfusion values is not associated with greater blood loss in liver transplant surgery. Liver Transpl 2012;18(10):1254-1258

105 Ferro D, Celestini A, Violi F. Hyperfibrinolysis in liver disease. Clin Liver Dis 2009;13(1):21-31

106 Porte RJ, Bontempo FA, Knot EA, Lewis JH, Kang YG, Starzl TE. Systemic effects of tissue plasminogen activator-associated fibrinolysis and its relation to thrombin generation in orthotopic liver transplantation. Transplantation 1989;47(6):978-984

107 Homatas J, Wasantapruek S, Von Kaulla E, Von Kaulla KN, Eiseman B. Clotting abnormalities following orthotopic and heterotopic transplantation of marginally preserved pig livers. Acta Hepatosplenol 1971;18(1):14-26

108 Porte RJ, Blauw E, Knot EA, et al. Role of the donor liver in the origin of platelet disorders and hyperfibrinolysis in liver transplantation. J Hepatol 1994;21(4):592-600

109 Görlinger K. [Coagulation management during liver transplantation]. Hamostaseologie 2006;26(3, Suppl 1):S64-S76

110 Schofield N, Sugavanam A, Thompson K, Mallett SV. No increase in blood transfusions during liver transplantation since the withdrawal of aprotinin. Liver Transpl 2014;20(5):584-590

111 Kang Y. Coagulation and liver transplantation. Transplant Proc 1993;25(2):2001-2005

112 Kang Y. Thromboelastography in liver transplantation. Semin Thromb Hemost 1995;21(Suppl 4):34-44

113 Harding SA, Mallett SV, Peachey TD, Cox DJ. Use of heparinase modified thrombelastography in liver transplantation. $\mathrm{Br} \mathrm{J}$ Anaesth 1997;78(2):175-179

114 Bezeaud A, Denninger MH, Dondero F, et al. Hypercoagulability after partial liver resection. Thromb Haemost 2007;98(6):1252-1256

115 Krzanicki D, Sugavanam A, Mallett S. Intraoperative hypercoagulability during liver transplantation as demonstrated by thromboelastography. Liver Transpl 2013;19(8):852-861

116 Schöchl H, Solomon C, Schulz A, et al. Thromboelastometry (TEM) findings in disseminated intravascular coagulation in a pig model of endotoxinemia. Mol Med 2011;17(3-4):266-272

117 Warnaar N, Molenaar IQ Colquhoun SD, et al. Intraoperative pulmonary embolism and intracardiac thrombosis complicating liver transplantation: a systematic review. J Thromb Haemost 2008;6(2):297-302

118 Xia VW, Ho JK, Nourmand H, Wray C, Busuttil RW, Steadman RH. Incidental intracardiac thromboemboli during liver transplantation: incidence, risk factors, and management. Liver Transpl 2010;16(12):1421-1427

119 Lerner AB, Sundar E, Mahmood F, Sarge T, Hanto DW, Panzica PJ. Four cases of cardiopulmonary thromboembolism during liver transplantation without the use of antifibrinolytic drugs. Anesth Analg 2005;101(6):1608-1612

120 Tripodi A, Mannucci PM. The coagulopathy of chronic liver disease. N Engl J Med 2011;365(2):147-156 